\title{
Something for the Future
}

\author{
John H. Mabry \\ University of North Carolina at Chapel Hill
}

Because the field of behavior analysis is intimately tied to generating useful applied knowledge, it seems reasonable to ask: To what use is our knowledge of verbal behavior to be put? Sundberg (1991) suggested second-language learning as worthy of experimentation. More specifically, I see any application as giving focus to a field that otherwise might join others in becoming merely academic.

Certainly second-language learning deserves a look. I think we know that the type of textbook teaching that occurred in our French, German, or Spanish classes in college or high school was inadequate. Some of the remembered parts of such courses followed familiar lines. Vocabulary was memorized from a list, and was used infrequently in examples. Tenses of standard verb forms were presented as tabled values by person and number (Ich bin, du bist, er ist, etc.); pronouns and articles by case and gender; transitive verbs were compared to intransitive verbs, and so forth. All the paraphernalia of formal grammatical analysis were available to the student but failed to impart a very substantial use of the language.

Even transliteration from a dictionary was mostly, not just sometimes, ridiculous. The question is: Can we do better? A recent book on second-language learning (Bialstok \& Hakuta, 1994) on the one hand extols the liberation of their science from the trials of empiricism via the cognitive revolution, but concludes nearly every chapter by admitting the failure of every major contribution from this quarter (a worthwhile book, by the way, if you want an introduction to the relevant research).

Address correspondence to the author at 2918 Wycliff Road, Raleigh, North Carolina 27607.
One immediate suggestion that could come from Skinner's Verbal Behavior (1957) is that the segmentation of speech into discrete words and parts of speech is neither efficient nor useful. There surely are others. What I am confident of is that in finding the answer of how to best teach a second language (just as happened in teaching children to tie their shoes) would bolster the whole technology and challenge the academic science.

A second area in which Verbal Behavior (1957) could be helpful to steer a course of future development is in the resurrection of programmed instruction (after all, we are approaching the millennium). Computerbased training, its most current congener, according to some sources, has faltered. The notion of getting a behavior up to strength and then gradually diminishing nonrelevant stimulus control, as has been the feature of much errorless programming, has not, it seems, progressed much in the direction of useful verbal programming. Chapters 9 and 10 of Verbal Behavior remind us of several sources of such manipulable features of verbal behavior that could form the basis of some technological innovation. Here I'm thinking of the thematic, intraverbal, and formal (echoic or textual) material or prompts that can obviously compete with or complement one another.

Another direction that seems at first blush to be largely of academic interest is the problem of "conditioned seeing" and "conditioned hearing" mentioned first in Science and Human Behavior (Skinner, 1953) but also in Verbal Behavior (Skinner, 1957, p. 158). In Science and Human Behavior Skinner wrote, "It has been shown experimentally that if one who is familiar with playing cards is briefly shown a heart printed in black ink, 
the heart is sometimes seen as red or as a mixture of red and black, perhaps reported as purple" (p. 267).

A similar phenomenon, called the McGurk effect, involves the simultaneous facial and visual presentation of a single repetitive phoneme or syllable. The visibly mouthed utterance clearly influences the "heard" sound. Kuhl and colleagues (e.g., Green \& Kuhl, 1991) have rather competently studied several parameters of the effect using traditional methods. There seems to be a number of parameters relevant to the individual speaker and listener that could be of both practical and theoretical value. Some of the conventional linguistic puzzles surrounding coarticulation, assimilation phenomena (cf. Crystal, 1997), or misarticulations such as substitutions and phonetic blends seem to beg interpretation as such perceptual conditioning. Why the Japanese listener is said not to be able to "hear" the L sound (as well as not say it) might be clarified if sound-to-sound (or sign-to-sign) differences were functions of conditioning of the same order. There are other demonstrable phenomena along this same line, such as the effect credited to McCollough (1965), often classed as a type of aftereffect. Here vertical black stripes are alternated with red and horizontal with green. The result is a persistent report of red or green when the black stripes are presented against white. Taken together, the two phenomena suggest that Skinner's notion of conditioned seeing (or hearing) as a type of classical conditioning is neither isolated nor rare.

Still needing clarification and persisting as a question for centuries is the general issue of the extensibility (generative or generalizability) of those things called by grammarians word classes or grammatical classes. A reasonably good summary can still be gained from Whitehurst (1982) who cites Maratsos and Chalkey (1980) (but ignore his concern with their list of "unsayable" sentences; cf. Mabry, 1993). Furthermore, a pursuit of this aged issue could help to clarify what we call stimulus class membership, a somewhat touchy subject in itself. Miniature artificial languages, similar to that employed by Braine (1963), should be a useful experimental paradigm for behavior analysis.
A final observation: We have been presented with several definitions of rule-governed behavior (cf. Catania, 1989; Glenn, 1989; Schlinger \& Blakely, 1987). I have read somewhere that Chomsky might claim first use of the term rule governed (but not contingency shaped), and his definition involving internal, algorithmically defined rules would not fit at all with any of our definitions. It would be helpful to arrive at a single (or a few) standard definition of rule, and, if we are unable to do so, cleanse our vocabulary altogether of the term. Perhaps a standards conference, in some quiet wooded area (within a train ride of Paris, perhaps), would not be too onerous to get me to volunteer to be a contributor.

\section{REFERENCES}

Bialstok, E., \& Hakuta, K. (1994). The science and psychology of second-language acquisition. New York: Basic Books.

Braine, M. D. S. (1963). On learning the grammatical order of words. Psychological Review, 70, 323-348.

Catania, A. C. (1989). Rules as classes of verbal behavior: A reply to Glenn. The Analysis of Verbal Behavior, 7, 49-50.

Crystal, D. (1997). The Cambridge encyclopedia of language (2nd ed.). Cambridge, UK: Cambridge University Press.

Glenn, S. (1989). On rules and rule-governed behavior: A reply to Catania's reply. The Analysis of Verbal Behavior, 7, 51-52.

Green, K. P., \& Kuhl, P. K. (1991). Integral processing of visual place and auditory voicing information during phonetic perception. Journal of Experimental Psychology: Human Perception and Performance, 17, 278-288.

Mabry, J. H. (1993). Comments on Skinner's grammar. The Analysis of Verbal Behavior, 11, 77-88.

Maratsos, M. P., \& Chalkey, M. A. (1980). The internal language of children's syntax: The ontogenesis and representation of syntactic categories. In K. Nelson (Ed.), Children's language (Vol. 2, pp. 127-214). New York: Gardner Press.

McCollough, C. (1965). Color adaptation of edge detectors in the human visual system. Science, 149, 11151116.

Schlinger, H., \& Blakely, E. (1987). Function-altering effects of contingency-specifying stimuli. The Behavior Analyst, 10, 27-45.

Skinner, B. F. (1953). Science and human behavior. New York: Macmillan.

Skinner, B. F. (1957). Verbal behavior. New York: Appleton-Century-Crofts.

Sundberg, M. L. (1991). Research topics from Skinner's book Verbal Behavior. The Analysis of Verbal Behavior, 9, 81-96.

Whitehurst, G. J. (1982). Language development. In B. J. Wolman (Ed.), Handbook of developmental psychology. Englewood Cliffs, NJ: Prentice Hall. 